\title{
CEFOXITIN, $N$-FORMIMIDOYL THIENAMYCIN, CLAVULANIC ACID, AND PENICILLANIC ACID SULFONE AS SUICIDE INHIBITORS FOR DIFFERENT TYPES OF $\beta$-LACTAMASES PRODUCED BY GRAM-NEGATIVE BACTERIA
}

\author{
Tetsuo Sawai and Kikuo Tsukamoto \\ Faculty of Pharmaceutical Sciences, Chiba University, Chiba, Japan
}

(Received for publication July 30, 1982)

\begin{abstract}
Cefoxitin, $N$-formimidoyl thienamycin (MK0787), clavulanic acid, and penicillanic acid sulfone $(\mathrm{CP} 45,899)$ were studied to determine their potency as suicide inhibitors of three very different kinds of $\beta$-lactamases produced by Gram-negative bacteria: type Ib penicillinase (TEM-2 type), a typical cephalosporinase (the enzyme of Proteus morganii), and a cephalosporinase with broad substrate specificity (the enzyme of Proteus vulgaris). All these $\beta$-lactams were confirmed to be quite stable to the three $\beta$-lactamases. The absolute values of the turnover numbers $\left(k_{\text {eat }}\right)$ for these enzyme-catalyzed hydrolyses were determined, the values ranged from 0.25 minute $^{-1}$ to 660 minute $^{-1}$. All the $\beta$-lactams studied, except cefoxitin, acted as suicide inhibitors of the typical cephalosporinase. Although cefoxitin did not exhibit such an effect, it was a powerful competitive inhibitor of this enzyme. Although the four $\beta$-lactams acted as suicide inhibitors of the $P$. vulgaris cephalosporinase, the inactivated enzyme partially regained its activity after removing the effect of the free inhibitor. Type Ib penicillinase was also inactivated by the four $\beta$-lactams, and the activity of the inactivated enzyme, except in the case of cefoxitin, was partially restored. The rate constants for enzyme inactivation or reactivation were calculated and are presented. The information obtained from this study suggests that the catalytic center of the $P$. vulgaris cephalosporinase is different not only from that of the penicillinase-type but also from that of the cephalosporinase-type $\beta$-lactamases.
\end{abstract}

It is well known that $\beta$-lactamase production in many pathogenic bacteria is closely associated with their resistance to $\beta$-lactam antibiotics. This association has created much interest in the development of $\beta$-lactamase-stable $\beta$-lactams or inhibitors of these enzymes as antibiotic-protecting agents. In the initial studies in this field, methicillin, oxacillin and its derivatives were discovered. These semisynthetic penicillins are very stable to many kinds of $\beta$-lactamases, but they show poor efficacy against Gramnegative bacteria because they are unable to penetrate the outer membrane of the bacterial cells $s^{1,2}$.

Recently, new types of $\beta$-lactams with novel ring structures such as clavulanic acid ${ }^{3)}$, cephamycins ${ }^{4)}$, penicillanic acid sulfone ${ }^{5)}$, carbapenems $^{6)}$, and $6-\beta$-bromopenicillanic acid ${ }^{7)}$ have been discovered. These $\beta$-lactams are stable to many types of $\beta$-lactamases, and it has been reported that some of them act as suicide inhibitors for the enzymes ${ }^{8 \sim 14)}$. The kinetic investigations on these suicide inhibitors have mainly been performed using one group of $\beta$-lactamases, namely, the TEM-type penicillinases. We were much interested in studying the kinetic behavior of many different types of $\beta$-lactamases toward these $\beta$-lactams since we expected that such an investigation would offer useful information about the characteristics of the catalytic site of the individual types of $\beta$-lactamases. We report herein some aspects of the mode of interaction of cefoxitin, $N$-formimidoyl thienamycin (MK0787), clavulanic acid, and penicillanic acid sulfone $(\mathrm{CP} 45,899)$ with three representative $\beta$-lactamases of Gram-negative bacteria: type Ib penicillinase (TEM-2 penicillinase), a typical cephalosporinase (the enzyme of Proteus morganii), and a cephalosporinase with broad substrate specificity (the enzyme of Proteus vulgaris). 


\section{Materials and Methods}

\section{Bacterial Strains}

The bacterial strains employed in this study were selected from those reported previously ${ }^{15)}$, which had been prepared in order to evaluate the $\beta$-lactamase-stability of $\beta$-lactam antibiotics. Escherichia coli ML1410 RGN14 and E. coli ML1410 RGN823 harbor R plasmids, RGN14 and RGN823, respectively. These plasmids mediate the constitutive production of type Ia and $\mathrm{Ib}$ penicillinases ${ }^{18)}$, respectively. Type Ia and type Ib penicillinases correspond to TEM-1 and TEM-2 penicillinases of MATTHEW'S classification $^{17)}$, respectively. E. coli ML1410 is an E. coil $\mathrm{K}-12$ substrain and is sensitive to $\beta$-lactam antibiotics.

$P$. vulgaris $\mathrm{GN} 76 / \mathrm{C}-1$ is a constitutive mutant with respect to its cephalosporinase production and was derived from the wild type strain GN76. The other two P. vulgaris strains, GN76/C-1/2 and GN76/ $\mathrm{C}-1 / 3$, were derived from strain $\mathrm{GN} 76 / \mathrm{C}-1$, and produce lower cephalosporinase activity than their parental strain.

P. morganii 1510 is a constitutive producer of a cephalosporinase; it was originally isolated from a clinical source by FuJII-KURIYAMA et al. ${ }^{18)}$. Strains $1510 / 3$ and $1510 / 9$, mutant strains with lower enzyme activity, were isolated by us from strain 1510 .

\section{B-Lactamases}

The three kinds of $\beta$-lactamases, namely, type Ib penicillinase and two cephalosporinases produced by $P$. vulgaris GN76/C-1 and P. morganii 1510, were used in this study. These two cephalosporinases are assumed to be mediated by chromosomal gene(s), and thought to be species-specific $\beta$-lactamases of the respective species.

Type Ib penicillinase was purified by a procedure reported previously ${ }^{18)}$. The $P$. morganii cephalosporinase was purified according to the procedure of FUJI-KuRIYAMA et al. ${ }^{18)}$. The purification of the $P$. vulgaris cephalosporinase was performed by adsorption and elution on CM-Sephadex C-50(Pharmacia Fine Chemicals) column and gel filtration on a Sephadex G-75(Pharmacia Fine Chemicals) column. The purity of these $\beta$-lactamase preparations was confirmed by polyacrylamide disc gel electrophore$\operatorname{sis}^{19,20)}$. Detailed information as to the properties of these three kinds of $\beta$-lactamases has been presented in a previous paper ${ }^{21)}$.

$\beta$-Lactams

The following $\beta$-lactams of established purities were kindly provided by the following pharmaceutical companies; benzylpenicillin and ampicillin, Meiji Seika Co., Tokyo, Japan; cephalothin and cephaloridine, Torii Pharmaceutical Co., Tokyo, Japan; cefoxitin and $N$-formimidoyl thienamycin (MK0787), Merck, Sharp \& Dohme Research Laboratories, Rahway, N. J., U.S.A.; clavulanic acid, Beecham Pharmaceuticals, Surrey, U.K. Penicillanic acid sulfone $(\mathrm{CP} 45,899)$ was synthesized in our laboratory from 6-aminopenicillanic acid.

\section{Assay for $\beta$-Lactam Hydrolysis}

For routine assay, $\beta$-lactamase activity was determined iodometrically at $30^{\circ} \mathrm{C}$ in $0.1 \mathrm{~m}$ phosphate buffer ( $\mathrm{pH}$ 7.0) by a colorimetric assay ${ }^{22}$. The kinetic measurement of the $\beta$-lactamase reaction was performed by a spectrophotometric method ${ }^{23}$ by measuring the change in ultraviolet absorption of the $\beta$-lactam ring at $30^{\circ} \mathrm{C}$ in $0.05 \mathrm{M}$ phosphate buffer ( $\mathrm{pH} 7.0$ ) with the aid of a Beckman model 24 spectrophotometer. The wavelengths used for the assay were $232 \mathrm{~nm}$ (benzylpenicillin), $265 \mathrm{~nm}$ (cephalothin), $270 \mathrm{~nm}$ (cefoxitin), $300 \mathrm{~nm}$ (MK0787), $230 \mathrm{~nm}$ (CP45,899), and $220 \mathrm{~nm}$ (clavulanic acid). These appropriate wavelengths were determined by complete hydrolysis of each $\beta$-lactam with a large excess of type Ib penicillinase or the $P$. morganii cephalosporinase.

\section{Estimation of $\mathrm{Ki}$ Value}

The $K i$ values of $\beta$-lactams for the $\beta$-lactamases were determined with benzylpenicillin (type Ib penicillinase) or cephalothin (the cephalosporinases) as substrate, and the values were estimated graphically from LINEWEAVER-BURK plots. 
Assay of Enzyme Inactivation by Pre-incubation with Cefoxitin, MK0787, Clavulanic Acid, and CP45,899

The enzyme preparation in $500 \mu 1$ of $0.05 \mathrm{M}$ phosphate buffer ( $\mathrm{pH} 7.0$ ) was pre-warmed at $30^{\circ} \mathrm{C}$, and then mixed with $25 \mu \mathrm{l}$ of the $\beta$-lactam dissolved in the same buffer. The final enzyme concentration in the mixture was $1 \mu \mathrm{M}$. The final $\beta$-lactam concentration was $1 \mu \mathrm{M}$ to $10 \mathrm{mM}$, and varied according to the sensitivity of the enzyme with respect to the $\beta$-lactam tested. The mixture was incubated at $30^{\circ} \mathrm{C}$. At appropriate time intervals, a portion $(50 \mu 1)$ was taken from the reaction mixture and diluted 600 to 1,000 -fold with the phosphate buffer. It was confirmed that this dilution precluded any further effect of the $\beta$-lactam on the enzyme activity. The enzyme activity remaining in the diluted reaction mixture was measured by the spectrophotometric method with $100 \mu \mathrm{M}$ benzylpenicillin (in the case of penicillinase) or $100 \mu \mathrm{m}$ cephalothin (in the case of cephalosporinases) as substrate.

\section{Antibiotic Sensitivity Testing}

Antibacterial activity of $\beta$-lactams was determined by a serial dilution method and expressed as the minimal inhibitory concentration (MIC, $\mu \mathrm{g} / \mathrm{ml}$ ). A detailed procedure has been reported. ${ }^{15)}$

\section{Results and Discussion}

Sensitivity of the $\beta$-Lactamase-producing Bacteria to $\beta$-Lactams

We measured the sensitivity of three groups of bacterial strains to the four $\beta$-lactams and to ampicillin and cephaloridine chosed as representatives of common $\beta$-lactam antibiotics. The three groups of bacteria produce different kinds of $\beta$-lactamases: type I penicillinase (the $E$. coli strains), a cephalosporinase with broad substrate specificity (the $P$. vulgaris strains) and a typical cephalosporinase (the $P$. morganii strains). All the bacterial strains in a given group produce the same or a similar kind of $\beta$ lactamase constitutively but the intracellular enzyme activity differs from strain to strain. The results shown in Table 1 confirm that the antibacterial activity of the new $\beta$-lactams is little affected by the bacterial production of $\beta$-lactamases. The antibacterial activity of cefoxitin, however, was slightly reduced by the typical cephalosporinase in $P$. morganii. In addition, $P$. vulgaris mutant strain, GN76/C-1/3, showed lower sensitivity to MK0787; the reason for this has not yet been determined.

Table 1. Antibacterial activity of $\beta$-lactam antibiotics and $\beta$-lactam analogues against $\beta$-lactamase-producing Gram-negative bacteria.

\begin{tabular}{|c|c|c|c|c|c|c|c|}
\hline \multirow{2}{*}{ Strain $^{b}$} & \multirow{2}{*}{$\begin{array}{l}\beta \text {-Lactamase activity } \\
\text { (units/mg dry weight } \\
\text { of bacteria) }\end{array}$} & \multicolumn{6}{|c|}{$\beta$-Lactam (MIC $\mu \mathrm{g} / \mathrm{ml})$} \\
\hline & & $\mathrm{APC}^{a}$ & CER & CFX & MK & CVA & $\mathrm{CP}$ \\
\hline E. coli ML1410 RGN823 & 16.7 & $>3200$ & 25 & 3.1 & 0.2 & 25 & 200 \\
\hline E. coli ML1410 RGN14 & 0.6 & 800 & 6.3 & 3.1 & 0.2 & 25 & 100 \\
\hline E. coli ML1410 & $<0.003$ & 3.1 & 3.1 & 3.1 & 0.2 & 25 & 100 \\
\hline P. vulgaris $\mathrm{GN} 76 / \mathrm{C}-1$ & 2.4 & 400 & 800 & 3.1 & 0.8 & 25 & 100 \\
\hline P. vulgaris $\mathrm{GN} 76 / \mathrm{C}-1 / 3$ & 0.03 & 25 & 200 & 3.1 & 3.1 & 25 & 100 \\
\hline P. vulgaris $\mathrm{GN} 76 / \mathrm{C}-1 / 2$ & $<0.01$ & 1.6 & 3.1 & 3.1 & 0.4 & 25 & 100 \\
\hline P. morganii 1510 & 2.68 & 400 & 400 & 12.5 & 1.6 & 50 & 200 \\
\hline P. morganii $1510 / 3$ & 0.07 & 50 & 100 & 6.3 & 0.8 & 50 & 200 \\
\hline P. morganii $1510 / 9$ & 0.006 & 1.6 & 6.3 & 3.1 & 1.6 & 50 & 100 \\
\hline $\begin{array}{lll}a \text { Abbreviations: } & \text { APC, } \\
& \text { (MK0 } \\
b \quad \text { See Materials and Meth }\end{array}$ & icillin; CER, cephalor & $\begin{array}{l}\text { idine; } \mathrm{CF} \text { ) } \\
\text { id; } \mathrm{CP} \text {, pe }\end{array}$ & $\begin{array}{l}\text { cefox } \\
\text { icillan }\end{array}$ & ; MF & $\begin{array}{l}\text {-form } \\
\text { ne }(C\end{array}$ & $\begin{array}{l}\text { doyl th } \\
, 899) \text {. }\end{array}$ & \\
\hline
\end{tabular}


Hydrolysis of the $\beta$-Lactams by the $\beta$-Lactamases and their Affinity for the Enzymes

The four $\beta$-lactams, cefoxitin, MK0787, clavulanic acid, and CP45,899 are well known to be quite stable to many kinds of $\beta$-lactamases ${ }^{3,4,6,24)}$. Consequently, it was very difficult to determine the absolute values of the turnover number $\left(k_{\mathrm{cat}}\right)$ for the $\beta$-lactamase-catalyzed hydrolysis of these $\beta$-lactams. We could determine the $k_{\text {eat }}$ values by incubating the $\beta$-lactams with a high concentration $(1 \mu \mathrm{M})$ of the pure enzyme preparation. From the initial velocity of the enzyme reaction, the $k_{\text {cat }}$ values were calculated and are listed in Table 2. Type $\mathrm{Ib}$ penicillinase and the $P$. vulgaris cephalosporinase showed relatively high hydrolytic activity against CP45,899 and clavulanic acid. However, these values were very low when compared with the $k_{\text {cat }}$ values of good substrates for these enzymes. For example, the $k_{\text {eat }}$ value for the hydrolysis of benzylpenicillin by type Ib penicillinase was reported to be $4.1 \times 10^{4}$ minute ${ }^{-121)}$. Similarly, the $k_{\text {cat }}$ values of cephaloridine hydrolysis by the $P$. vulgaris cephalosporinase and the $P$. morganii cephalosporinase were reported to be $2.0 \times 10^{4}$ minute $^{-1}$ and $3.3 \times 10^{3}$ minute $^{-1}$, respectively ${ }^{21)}$.

In order to estimate the affinity between the $\beta$-lactams and the enzymes, the dissociation constant, $K i$, of the enzyme- $\beta$-lactam complex was determined. The enzyme was used as a much more dilute solution for assaying $\beta$-lactamase activity in the presence of a good substrate. Therefore, the change in ultraviolet absorption due to hydrolysis of the inhibitors was negligible. The $K i$ values were also calculated from the initial velocities determined after a short reaction time ( 2 minutes) in order to avoid the suicide effect of the $\beta$-lactam on the enzyme activity. The $K i$ values obtained are listed in Table 2. An interesting tendency was found not only with respect to the hydrolytic activity of the three $\beta$-lactamases toward the $\beta$-lactams, but also with respect to their affinity for the $\beta$-lactams. Cefoxitin showed a very high $K i$ value for type Ib penicillinase, indicating its very low affinity for the enzyme. However, the affinity of cefoxitin increased greatly with the increasing cephalosporinase-type character of the enzyme. In contrast, clavulanic acid showed high affinity for the penicillinase but exhibited low affinity for the typical cephalosporinase, i.e., the P. morganii cephalosporinase. A similar tendency was found in the case of CP45,899. The carbapenem $\beta$-lactam, MK0787, showed high affinity for all three kinds of $\beta$ lactamases tested.

It is also an interesting fact that the $P$. vulgaris cephalosporinase had a behaviour intermediate between the cephalosporinase-type and the penicillinase-type $\beta$-lactamases with respect to its affinity for the inhibitors as well as its substrate profile determined with common $\beta$-lactam antibiotics ${ }^{21}$.

Table 2. Kinetic constants of three $\beta$-lactamases using cefoxitin, MK0787, clavulanic acid, and CP45,899.

\begin{tabular}{|c|c|c|c|c|c|c|}
\hline \multirow[t]{2}{*}{$\beta$-Lactam ${ }^{a}$} & \multicolumn{2}{|c|}{ Type Ib penicillinase } & \multicolumn{2}{|c|}{$\begin{array}{l}\text { Cephalosporinase } \\
\text { of } P \text {. vulgaris }\end{array}$} & \multicolumn{2}{|c|}{$\begin{array}{l}\text { Cephalosporinase } \\
\text { of } P \text {. morganii }\end{array}$} \\
\hline & $k_{\text {cat }}{ }^{b}$ & $K i(\mu \mathrm{M})$ & $k_{\text {cat }}$ & $K i(\mu \mathrm{M})$ & $k_{\text {eat }}$ & $K i(\mu \mathrm{M})$ \\
\hline Cefoxitin & 0.25 & 556 & 0.50 & 4.2 & 0.94 & 0.28 \\
\hline MK0787 & 6.2 & 3.1 & 2.4 & 0.31 & 0.29 & 1.7 \\
\hline Clavulanic acid & 660 & 0.5 & 42 & 0.35 & 3.4 & 1,100 \\
\hline CP45,899 & 350 & 0.5 & 180 & 2.1 & 0.63 & 8.9 \\
\hline
\end{tabular}

a The four $\beta$-lactams were used as substrates for determination of $k_{\text {cat }}$ values and as inhibitors for determination of $K i$ values.

${ }_{b} \quad k_{\text {eat }}$ : molecules of $\beta$-lactam hydrolyzed per minute per molecule of $\beta$-lactamase at pH 7.0 and $30^{\circ} \mathrm{C}$. 
The Inhibition of the Three $\beta$-Lactamases by Cefoxitin, MK0787,

Clavulanic Acid and CP45,899

Clavulanic acid and CP45,899 have been reported to be irreversible inhibitors for some kinds of $\beta$ lactamases $^{8, \theta)}$. These $\beta$-lactams are thought to act as 'suicide inhibitors or progressive inhibitors' of $\beta$-lactamases. The mechanisms of this reaction has been extensively studied for a limited number of $\beta$ lactamases, namely penicillinases ${ }^{8 \sim 14}$.

The irreversible inhibition of the three types of $\beta$-lactamases studied by the four $\beta$-lactams was measured by pre-incubating the enzyme with the $\beta$-lactam for different time periods according to the procedure described in Materials and Methods. The results are shown in Fig. 1.

Fig. 1A shows the effect of cefoxitin on the activity of the three kinds of $\beta$-lactamases. The activity of the penicillinase was completely reduced in the presence of $10 \mathrm{~mm}$ cefoxitin within a few minutes of preincubation. A stronger inhibitory effect was observed on the $P$. vulgaris cephalosporinase though recovery of enzyme activity was observed. Cefoxitin is a powerful competitive inhibitor of the $P$. morganii cephalosporinase ${ }^{2)}$. We did not observe an irreversible inhibitory effect on the cephalosporinase even with $2 \mathrm{~mm}$ cefoxitin. This finding is in agreement with the results shown in Table 1 and with our previous observations that the $E$. coli strains producing the $\mathrm{R}$ plasmid-mediated penicillinases and the

Fig. 1. Inactivation of the three kinds of $\beta$-lactamases with cefoxitin, MK0787, clavulanic acid, and CP45,899 .

The enzyme solution $(1 \mu \mathrm{M})$ was incubated at $30^{\circ} \mathrm{C}$ with the indicated concentrations of the $\beta$-lactam, and the remaining enzyme activity was measured after various incubation times by the procedure described in Materials and Methods. $\beta$-Lactams tested: Fig. 1A, cefoxitin; Fig. 1B, MK0787; Fig. 1C, clavulanic acid; Fig. 1D, CP45,899. $\beta$-Lactamases tested: (a), type Ib penicillinase; (b), the $P$. vulgaris cephalosporinase; (c), the $P$. morganii cephalosporinase.

A
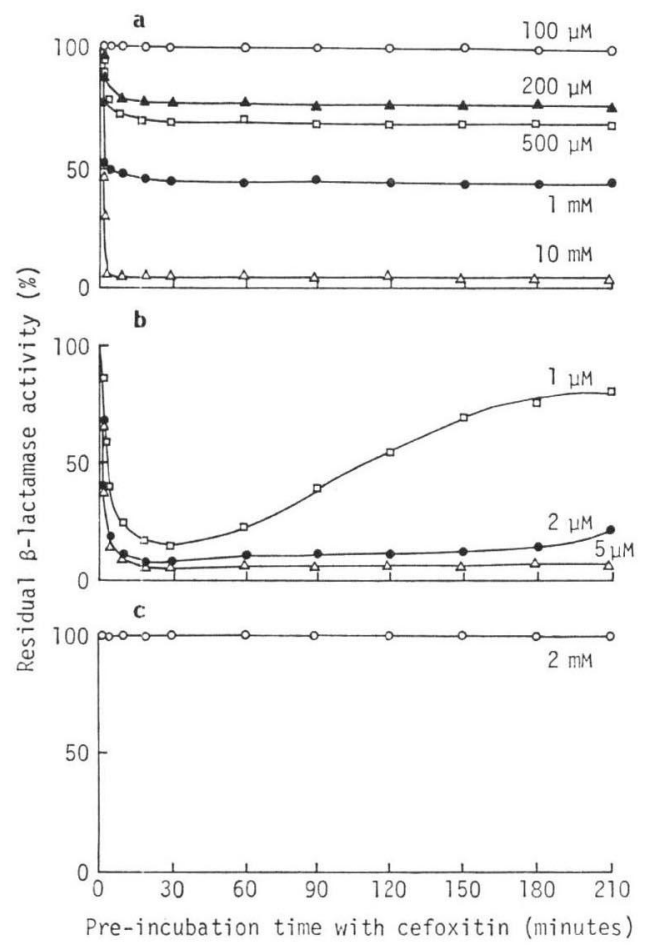

B

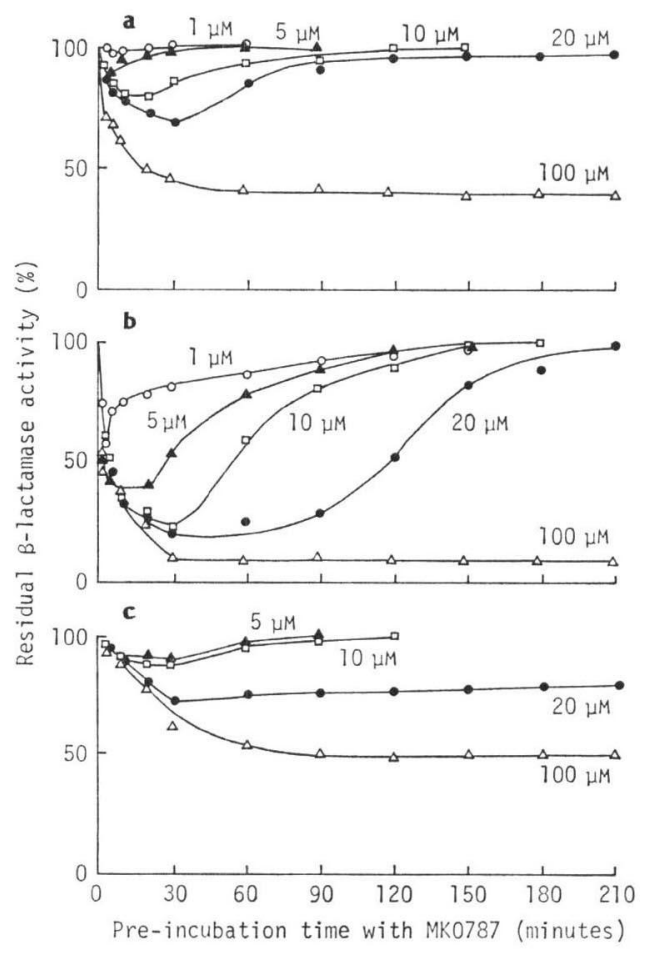


$\mathrm{C}$

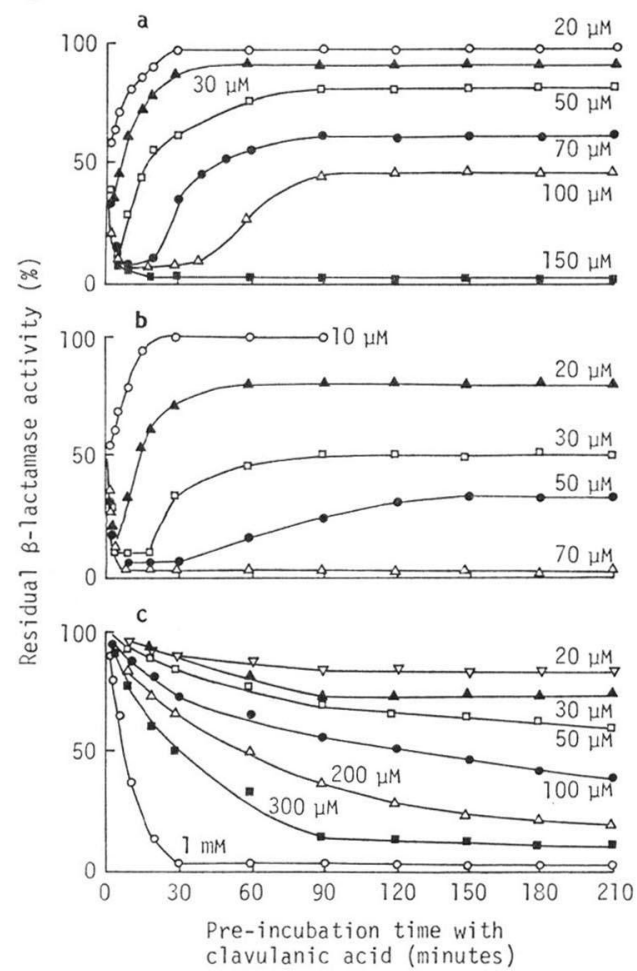

$\mathrm{D}$

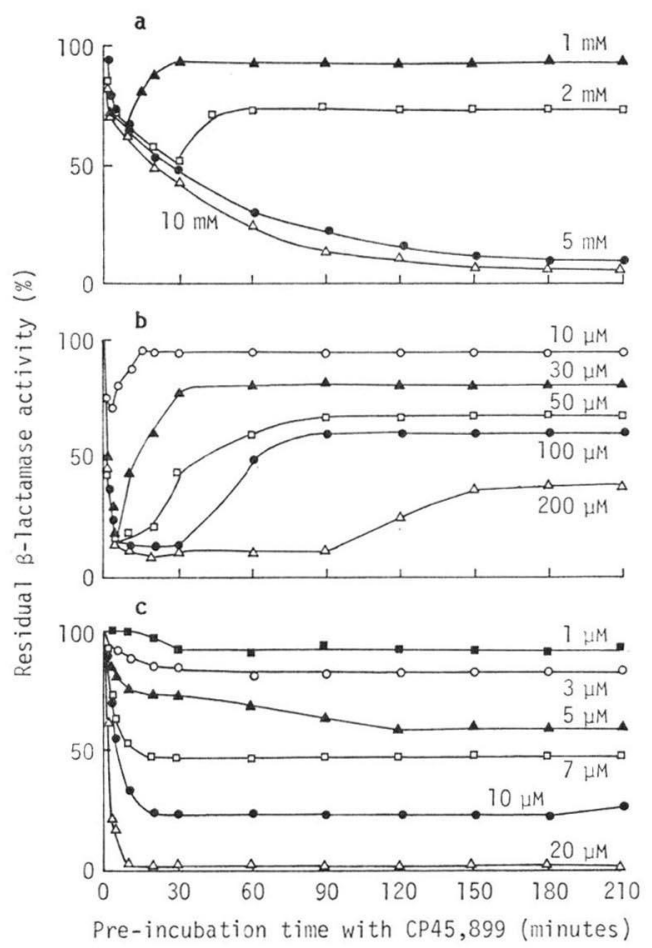

$P$. vulgaris strains producing the cephalosporinase are highly sensitive to cefoxitin though the typical cephalosporinase-producers in P. morganii, Citrobacter freundii, and Enterobacter cloacae are highly resistance to cefoxitin ${ }^{15)}$. Such a phenomenon may be attributed to a difference in the mode of cefoxitin reaction with the enzymes, i.e., suicide inhibition or competitive inhibition of the $\beta$-lactamases.

All the $\beta$-lactamases tested showed reduced activity when pre-incubated with MK0787, and it was found that the $P$. vulgaris cephalosporinase was most susceptible to the inhibitor (Fig. 1B). When treated with relatively low concentrations of MK0787, complete recovery of the activity was observed for all the $\beta$-lactamases tested. The pre-incubation experiment, however, indicated that MK0787 acted as a suicide inhibitor for all the $\beta$-lactamases tested. This finding is consistent with the recent observation by RiCHMOND ${ }^{25)}$.

More than $80 \%$ of the activities of type Ib penicillinase and the $P$. vulgaris cephalosporinase were inactivated with clavulanic acid concentrations higher than $50 \mu \mathrm{M}$ and $20 \mu \mathrm{M}$, respectively, within a few minutes of pre-incubation (Fig. 1C). Clavulanic acid has been reported to be active against penicillinases, but not cephalosporinases ${ }^{26)}$. Our observations confirmed that clavulanic acid is a potent inhibitor against the penicillinase-type enzyme, but we also showed that clavulanic acid is a powerful suicide inhibitor of the $P$. vulgaris cephalosporinase. The activity of the inactivated form of these two $\beta$-lactamases was partially restored at a relatively rapid rate. This fact is in striking contrast to that observed for the $P$. morganii cephalosporinase. This cephalosporinase was inactivated irreversibly by incubation with the inhibitor though a higher concentration and a prolonged incubation period were required for successful inhibition.

In contrast to clavulanic acid, CP45,899 was shown to be a powerful suicide inhibitor of the typical 
cephalosporinase, the $P$. morganii cephalosporinase. Inactivation with CP45,899 was observed after pre-incubation for 30 minutes (Fig. 1D). The degree of apparent irreversible inactivation was proportional to the increase of $\mathrm{CP} 45,899$ concentrations. It is interesting to note that the potency of CP45,899 as a suicide inhibitor decreased as the penicillinase-type character of the enzyme increased.

Except in the case of the $P$. morganii cephalosporinase and cefoxitin, the activity of the $\beta$-lactamases tested decreased as the time of pre-incubation with the $\beta$-lactam increased. Since the plot of the $\%$ of residual activity (log scale) versus pre-incubation time is linear, the inactivation process was assumed to follow first order kinetics (Fig. 2). This time-dependent inactivation is good evidence of covalent-bond

Table 3. Kinetic parameters of inactivation and reactivation.

\begin{tabular}{|c|c|c|c|c|c|c|}
\hline \multirow{2}{*}{$\beta$-Lactam } & \multicolumn{2}{|c|}{ Type Ib penicillinase } & \multicolumn{2}{|c|}{$\begin{array}{c}\text { Cephalosporinase of } \\
P . \text { vulgaris }\end{array}$} & \multicolumn{2}{|c|}{$\begin{array}{c}\text { Cephalosporinase of } \\
P . \text { morganii }\end{array}$} \\
\hline & $\begin{array}{c}k_{\text {1nact }} \\
\text { (minute }^{-1} \text { ) } \\
t_{1 / 2} \text { of inact. } \\
\text { (minutes) }\end{array}$ & $\begin{array}{c}k_{\text {react }} \\
\text { (minute }^{-1} \text { ) } \\
t_{1 / 2} \text { of react. } \\
\text { (minutes) }\end{array}$ & $\begin{array}{c}k_{\text {inact }} \\
\left.\text { (minute }^{-1}\right) \\
t_{1 / 2} \text { of inact. } \\
\text { (minutes) }\end{array}$ & $\begin{array}{c}k_{\text {react }} \\
\text { (minute }^{-1} \text { ) } \\
t_{1 / 2} \text { of react. } \\
\text { (minutes) }\end{array}$ & $\begin{array}{c}k_{\text {inact }} \\
\text { (minute }^{-1} \text { ) } \\
t_{1 / 2} \text { of inact. } \\
\text { (minutes) }\end{array}$ & $\begin{array}{c}k_{\text {react }} \\
\text { (minute }{ }^{-1} \text { ) } \\
t_{1 / 2} \text { of react. } \\
\text { (minutes) }\end{array}$ \\
\hline \multirow{2}{*}{ Cefoxitin } & $7.4 \times 10^{-1}$ & & $3.5 \times 10^{-1}$ & $1.4 \times 10^{-2}$ & & \\
\hline & 0.94 & & 2.0 & 50 & & \\
\hline \multirow{2}{*}{ MK0787 } & $1.9 \times 10^{-2}$ & $2.3 \times 10^{-2}$ & $6.5 \times 10^{-2}$ & $2.2 \times 10^{-2}$ & $1.7 \times 10^{-2}$ & $6.5 \times 10^{-2}$ \\
\hline & & & & 32 & 41 & 11 \\
\hline \multirow{2}{*}{ Clavulanic acid } & $3.5 \times 10^{-1}$ & $8.4 \times 10^{-2}$ & $3.3 \times 10^{-1}$ & $1.4 \times 10^{-1}$ & $1.0 \times 10^{-1}$ & \\
\hline & 2.0 & 8.3 & 2.1 & 5.0 & 6.9 & \\
\hline \multirow{2}{*}{$\mathrm{CP} 45,899$} & $3.2 \times 10^{-2}$ & $1.1 \times 10^{-1}$ & $2.9 \times 10^{-1}$ & $5.5 \times 10^{-2}$ & $1.2 \times 10^{-1}$ & \\
\hline & & 6.3 & 2.4 & 13 & 5.8 & \\
\hline
\end{tabular}

Fig. 2. Semilogarithmic plots of the rate of inactivation of the three $\beta$-lactamases in the presence of the four $\beta$-lactams.

Type Ib penicillinase (O), the $P$. vulgaris cephalosporinase ( $)$, and the $P$. morganii cephalosporinase $(\triangle)$ were examined by the procedure described in Fig. 1 and the Materials and Methods section. Cefoxitin concentrations were: $\mathrm{O}, 10 \mathrm{~mm} ; \bullet, 5 \mu \mathrm{M} ; \Delta, 2 \mathrm{~mm}$. MK0787 concentrations were: $\bigcirc, 100 \mu \mathrm{M} ; \bullet$, $100 \mu \mathrm{M} ; \Delta, 100 \mu \mathrm{M} . \quad \mathrm{CP} 45,899$ concentrations were; $\bigcirc, 10 \mathrm{mM} ;-200 \mu \mathrm{M} ; \Delta, 10 \mu \mathrm{M}$. Clavulanic acid concentrations were: $\bigcirc, 150 \mu \mathrm{M} ; \bullet, 70 \mu \mathrm{M} ; \triangle, 1 \mathrm{~mm}$.
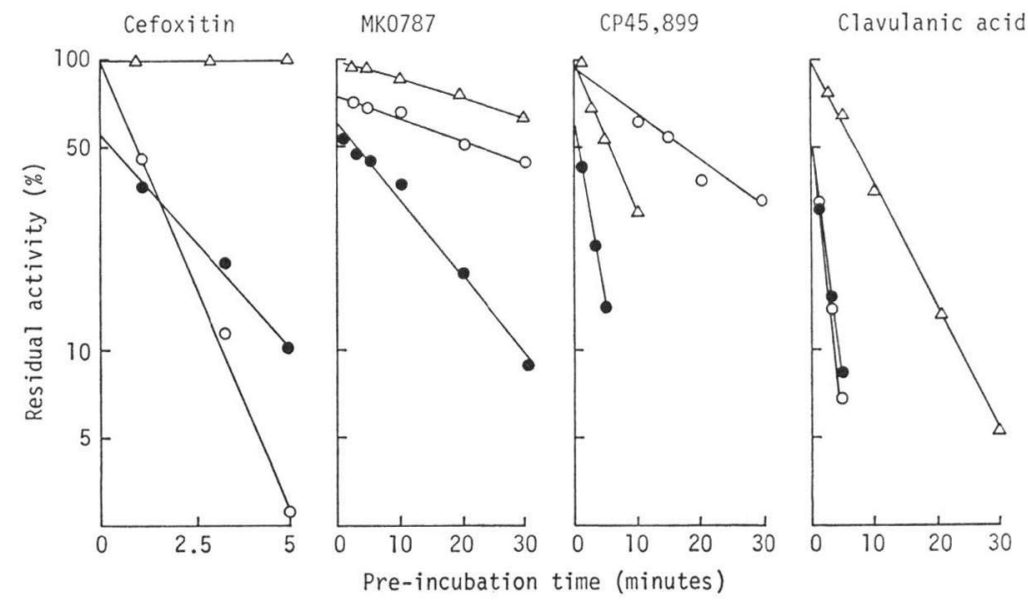
Fig. 3. Semilogarithmic plots of the reactivation rate of the inhibited $\beta$-lactamases.

The inactivated enzyme fraction of type Ib penicillinase $(O)$, the $P$. vulgaris cephalosporinase $(-)$, or the $P$. morganii cephalosporinase $(\Delta)$ was plotted against the pre-incubation time. The inhibitor concentrations were as follows. Cefoxitin: $1 \mu \mathrm{M}$. MK0787: $0,20 \mu \mathrm{M} ; \bullet, 5 \mu \mathrm{M} ; \Delta$, $10 \mu \mathrm{M}$; CP45,899: O, $1 \mathrm{~mm}$; $30 \mu \mathrm{M}$. Clavulanic acid: $0,20 \mu \mathrm{M} ; \bullet, 10 \mu \mathrm{M}$.

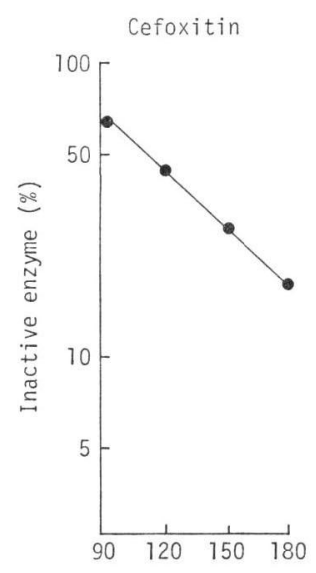

MK0787

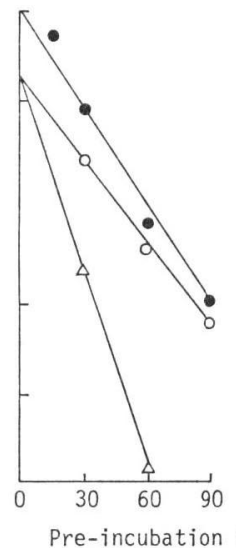

CP45,899

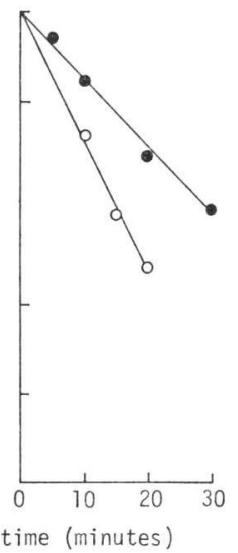

Clavulanic acid

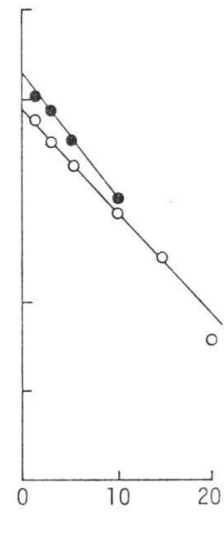

formation between inhibitor and enzyme ${ }^{27)}$. The rate constants $\left(k_{\text {in act }}\right)$ calculated from the experimental curves in Fig. 2, are shown in Table 3 together with the half-life $\left(t_{1 / 2}\right)$ of inactivation. The $k_{\text {inact }}$ value depends on the inhibitor concentration, therefore, a direct comparison of the values obtained at different inhibitor concentrations is unsuitable for an indication of inhibitory activity. However, the $k_{\text {inact }}$ values in Table 3 may perhaps be used for an understanding of relative inhibitory activities of the $\beta$ lactams against the three $\beta$-lactamases.

As observed in Figs. 1A, 1B, 1C, and 1D, an apparent irreversible inhibition of the enzyme activity was demonstrated in the following three cases: cefoxitin inhibition of type Ib penicillinase, clavulanic acid and CP45,899 inhibition of the P. morganii cephalosporinase. For the other combinations, recovery of enzyme activity was observed after hydrolysis of the inhibitors in the medium. The regain of activity was found to depend on the $\beta$-lactam concentrations. Since the $\%$ of reactivated enzyme (log scale) versus pre-incubation time could be plotted on a straight line, this suggest that the reactivation process also followed first-order kinetics (Fig. 3). The calculated rate constants of reactivation, $k_{\text {react }}$, are shown in Table 3 together with the values of the half-life $\left(t_{1 / 2}\right)$ of reactivation.

On the basis of the results of this comparative kinetic study involving three types of $\beta$-lactamases and four $\beta$-lactam inhibitors, we suggest that the catalytic center of the $P$. vulgaris cephalosporinase more closely resembles that of the penicillinase-type than that of the typical cephalosporinase-type $\beta$-lactamase.

\section{References}

1) Nikaido, H.: Outer membrane of Salmonella typhimurium, transmembrane diffusion of some hydrophobic substances. Biochim. Biophys. Acta 433: 118 132, 1976

2) SAWAI, T. \& T. Yoshida: A simple method for testing the efficacy of a $\beta$-lactamase inhibitor against $\beta$ lactamase-producing Gram-negative bacteria. J. Antibiotics 35: 1072 1077, 1982

3) Brown, A. G.; D. Butterworth, M. Cole, G. Hanscomb, J. D. Hood, C. Reading \& G. N. Rolinson: Naturally occurring $\beta$-lactamase inhibitors with antibacterial activity. J. Antibiotics 29: 668 669, 1976

4) Onishi, H. R.; D. R. Daoust, S. B. Zimmerman, D. Hendlin \& E. O. Stapley: Cefoxitin, a semisynthetic 
cephamycin antibiotic: resistance to beta-lactamase inactivation. Antimicrob. Agents Chemother. 5: 38 48, 1974

5) English, A. R.; J. A. Retsema, A. E. Girard, J. E. Lynch \& W. E. Barth: CP45,899, a beta-lactamase inhibitor that extends the antibacterial spectrum of beta-lactams: Initial bacteriological characterization. Antimicrob. Agents Chemother. 14: 414 419, 1978

6) Brown, A. G.; D. F. Corbett, A. J. Eglington \& T. T. Howarth: Structure of olivanic acid derivatives MM4550 and MM13902: Two new fused $\beta$-lactams isolated from Streptomyces olivaceus. J. Chem. Soc., Chem. Commun. 1977: 523 525, 1977

7) Pratt, R. F. \& M. J. Loosemore: 6- $\beta$-Bromopenicillanic acid, a potent $\beta$-lactamase inhibitor. Proc. Natl. Acad. Sci., U. S. A. 75: 4145 4149, 1978

8) Fisher, J.; R. L. Charnas \& J. R. Knowles: Kinetic studies on the inactivation of Escherichia coli RTEM $\beta$-lactamase by clavulanic acid. Biochemistry 17: $2180 \sim 2184,1978$

9) Labia, R.; V. Leliever \& J. Peduzzi: Inhibition kinetics of three R-factor-mediated $\beta$-lactamases by a new $\beta$-lactam sulfone (CP45899). Biochim. Biophys. Acta 661: $351 \sim 357,1980$

10) Readivg, C. \& P. Hepburn: The inhibition of Staphylococcal $\beta$-lactamase by clavulanic acid. Biochem. J. $179: 67 \sim 76,1979$

11) Fisher, J.; G. Belasco, R. L. Charnas \& S. Khosla: $\beta$-Lactamase inactivation by mechanism-based reagents. Phil. Trans. R. Soc. Lond. B 289: 309 319, 1980

12) Fisher, J.; R. L. Charnas, S. M. Bradley \& J. R. Knowles: Inactivation of the RTEM $\beta$-lactamase from Escherichia coli. Interaction of penam sulfone with enzyme. Biochemistry 20: 2726 2731, 1981

13) Charnas, R. L. \& J. R. KNowles: Inactivation of RTEM $\beta$-lactamase from Escherichia coli by clavulanic acid and 9-deoxyclavulanic acid. Biochemistry 20: 3214 3219, 1981

14) ReAdivg, C. \& T. FARmer: The inhibition of $\beta$-lactamases from Gram-negative bacteria by clavulanic acid. Biochem. J. 199: 779 787, 1981

15) Sawai, T.; T. Yoshida, K. Tsukamoto \& S. Yamagishi: A set of bacterial strains for evaluation of $\beta$ lactamase-stability of $\beta$-lactam antibiotics. J. Antibiotics 34: 1318 1326, 1981

16) Sawai, T.; K. Takahashi, S. Yamagishi \& S. Mitsuhashi: Variant of penicillinase mediated by R factor in Escherichia coli. J. Bacteriol. 104: 620 629, 1970

17) Matthew, M. \& R. W. Hedges: Analytical isoelectric focusing of R-factor-determined $\beta$-lactamases: Correlation with plasmid compatibility. J. Bacteriol. 125: 713 718, 1976

18) Fuji-Kuriyama, Y.; M. Yаmamoto \& S. Sugawara: Purification and properties of beta-lactamase from Proteus morganii. J. Bacteriol. 131: 726 734, 1977

19) Davis, B. J.: Disc electrophoresis. II. Method and application to human serum proteins. Ann. New York Acad. Sci. 121: 404 427, 1964

20) Reisfeld, R. A.; U. J. Lewis \& D. E. Wiliams: Disc electrophoresis of basic proteins and peptides on polyacrylamide gels. Nature (London) 195: 281 283, 1962

21) Sawai, T.; M. Kanno \& K. Tsukamoto: Characterization of eight $\beta$-lactamases of Gram-negative bacteria. J. Bacteriol. 152 (2): 1982, in press

22) SAWAI, T.; I. TAKAHASHI \& S. YAmagishi: Iodometric assay method for beta-lactamase with various betalactam antibiotics as substrates. Antimicrob. Agents Chemother. 13: 910 913, 1978

23) O'Callaghan, C. H.; P. W. Muggleton \& C. W. Ross: Effect of $\beta$-lactamase from Gram-negative organisms on cephalosporins and penicillins. Antimicrob. Agents Chemother.-1968: 57 63, 1969

24) Kahan, J. S.; F. M. Kahan, E. O. Stapley, R. T. Geogelman \& R. Hernandez: US Patent No. 3,950, April 13, 1976

25) Richmond, M. H.: The semi-synthetic thienamycin derivative MK0787 and its properties with respect to a range of $\beta$-lactamases from clinically relevant bacterial species. J. Antimicrob. Chemother. 7: 279 285, 1981

26) Reading, C. \& M. Cole: Clavulanic acid: a beta-lactamase-inhibiting-beta-lactam from Streptomyces clavuligerus. Antimicrob. Agents Chemother. 11: 852 857, 1977

27) Abeles, R. H. \& A. L. Mаусоск: Suicide enzyme inhibitors. Acc. Chem. Res. 9: 313 319, 1976 